\title{
Tobacco smoking among nursing students in Saudi Arabia: A descriptive correlational study
}

\author{
Ahmad H. Abu Raddaha ${ }^{* 1}$, Amirat A. Al-Sabeely ${ }^{1,2}$, Heba M. Mohamed ${ }^{1}$, Eid H. Aldossary ${ }^{1}$ \\ ${ }^{1}$ Department of Nursing, College of Applied Medical Sciences, Prince Sattam bin Abdulaziz University, Alkharj, Kingdom of \\ Saudi Arabia \\ ${ }^{2}$ Department of Pediatric Health Nursing, Faculty of Nursing, Zagazig University, Egypt
}

Received: February 26, 2017

DOI: $10.5430 /$ jnep.v7n10p98
Accepted: May 16, 2017

Online Published: May 25, 2017

URL: https://doi.org/10.5430/jnep.v7n10p98

\begin{abstract}
Background and objectives: Tobacco smoking is a global epidemic and health threat that continues to increase. Nursing students primarily develop their professional roles toward smoking cessation during their academic nursing education. We assessed prevalence and behavioral patterns of tobacco smoking among nursing students. Along with nature of education received on tobacco smoking cessation, we sought to explore their knowledge, attitudes and beliefs toward tobacco smoking.

Methods: Using convenience sampling, a descriptive correlational research design was used. Subjects were undergraduate students from a public university located in Alriyadh, the capital of Saudi Arabia. A standardized self-administered questionnaire, the Global Health Professional Student Survey, was utilized.

Results: Eighty-four percent reported not smoking tobacco throughout their lifetime (i.e., never smokers), while the remaining were former smokers. Although $11.7 \%$ indicated that they had received formal training on tobacco-smoking cessation, more former smokers reported receiving such formal training than never smokers ( $25 \%$ vs. 9.3\%, $\chi^{2}=4.04$, $\left.\mathrm{df}=1, p=.04\right)$. Students who were in third year of program, who thought that a smoker who quits smoking tobacco products would avoid/decrease serious health problems, and who stated that tobacco smoking never been allowed inside their living homes while children were present were more likely be never smokers.

Conclusions: Adding training modules on smoking cessation to undergraduate nursing program curricula is highly suggested. Considering our unique findings on the effect of smoking status on the attitudes and beliefs toward smoking among nursing students when planning and implementing training modules seems beneficial. Future research is recommended to explore the lived experiences and consequences of smoking behavior among former smokers group.
\end{abstract}

Key Words: Knowledge, Nursing students, Saudi Arabia, Smoking, Tobacco use

\section{INTRODUCTION}

\subsection{Background}

According to the World Health Organization, ${ }^{[1]}$ tobacco smoking is a global problem that continues to increase and encompass the biggest health threat the world has ever faced, killing around 6 million people each year. Tobacco smoking remains highly prevalent despite health hazards of smoking tobacco products. In 2015, it was estimated that $16.7 \%$ of adult men and $13.6 \%$ of adult women in the US were smokers. ${ }^{[2]}$ In the most recent statistics in 2013 among adult Saudis, tobacco smoking prevalence was estimated at $23.7 \%$ in men and $1.5 \%$ in women. ${ }^{[3]}$

\footnotetext{
*Correspondence: Ahmad H. Abu Raddaha; Email: a.aburaddaha@psau.edu.sa; Address: Nursing Department, College of Applied Medical Sciences, Prince Sattam bin Abdulaziz University, P.O. Box: 422, Alkharj, 11942, Kingdom of Saudi Arabia.
} 
Nurses play significant key roles in tobacco use prevention and cessation interventions. ${ }^{[4]}$ While studying at academic settings, nursing students develop their professional roles in giving help to smokers who wish to quit. Consequently, it is pressingly necessary to explore tobacco smoking history and behaviors, knowledge, attitudes, and beliefs towards smoking among nursing students, and to have an insight into the nature of education they receive on smoking cessation.

\subsection{Research objectives}

The objectives of this study were to assess the prevalence and behavioral patterns of tobacco smoking among undergraduate nursing program students, to explore their knowledge, attitudes, and beliefs towards smoking according to the Global Health Professional Student Survey approach, and to develop an insight into the nature of education they receive on smoking cessation.

\subsection{Literature review}

Tobacco smoking is a major health threat to both the smokers themselves and the public due to second- and third-hand tobacco smoke exposure. ${ }^{[1]}$ Cessation of tobacco smoking behavior reduces health risks and improves quality of life. ${ }^{[5-8]}$ Smokers should be encouraged by the healthcare providers, such as physicians and nurses, to quit smoking. ${ }^{[9]}$ However, one of the barriers in achieving smoking cessation is the prevalence of smoking amongst healthcare providers. ${ }^{[10,11]}$

Several international research studies examined tobacco use among college students. ${ }^{[7,9,10,12-23]}$ In Saudi Arabia, two studies investigated tobacco use among medical college students $^{[24,25]}$ and one study targeted dental students. ${ }^{[26]}$ One study published in the previous century ${ }^{[27]}$ explored the knowledge and attitude toward smoking among nursing and medical laboratory technology students and interns. In addition, a census was conducted in 2010 on nursing students in Saudi Arabia. ${ }^{[28]}$

In a cross-sectional study on a sample of 266 students and interns (152 nursing and 114 medical laboratory technology) in Eastern Province of Saudi Arabia, Mandil et al. ${ }^{[27]}$ found that the overall smoking prevalence was low (5.6\%). Further, knowledge deficit on the addictive nature of smoking was noted. In the same light, the Global Health Professional Student Survey questionnaire was used in a census conducted in 2010 on 127 nursing students in Saudi Arabia. The findings showed that $53.3 \%$ of them ever smoked cigarettes and $37.1 \%$ ever used any form of tobacco other than cigarettes. Further, $19.9 \%$ and $20.4 \%$ were current cigarettes and waterpipe (also called: narghile, shisha, hookah) smokers, respectively. Most students $(87.1 \%)$ supported a ban on smoking in all enclosed public places, and almost a quarter (24\%) reported receiv-

Published by Sciedu Press ing training in smoking cessation approaches to use with patients. $^{[28]}$

In a study assessed the prevalence and knowledge of smoking among female medical students in comparison to female non-medical students in a governmental university in Saudi Arabia, ${ }^{[25]}$ the prevalence of smoking was higher in nonmedical female students $(4.2 \%)$ compared to medical female students $(0.32 \%)$. Among Saudi male and female medical students, Al-Haqwi et al. ${ }^{[24]}$ conducted a study to assess the prevalence of smoking and the attitudes and practices as well as their knowledge on the risk factors of tobacco consumption. They found that $19 \%$ indicated that they smoke tobacco. However, all of the subjects were males. Interestingly, 94\% indicated that smoking could cause serious illnesses; $90 \%$ indicated that they would advise their patients to quit smoking in the future, and $88 \%$ reported that smoking should be banned in public areas. In another study in Saudi Arabia, Awan et al. ${ }^{[26]}$ conducted a study to evaluate current knowledge of and attitudes toward smoking and its cessation among general dental practitioners and dental students. They found that $33.8 \%$ of general dental practitioners and $30.2 \%$ of dental students were smokers.

In a cross-sectional national survey conducted in 2009 among Greece nursing students, Patelarou et al. ${ }^{[10]}$ found that $33 \%$ were current active smokers, while $74 \%$ had experimented smoking in their lifetime. The prevalence of smoking among

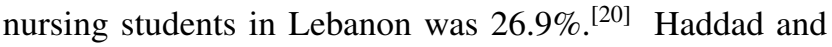
Malak, ${ }^{[15]}$ in a study among university students in Jordan, found that prevalence of smoking among females was $6.5 \%$ but $50.2 \%$ among males. Cui et al. ${ }^{[14]}$ conducted a study in China on 150 college student smokers to investigate their attitudes toward smoking. They found higher positive attitudes toward smoking among female smokers when compared to male smokers. In Italy, Ferrante et al. ${ }^{[9]}$ conducted a study among health professional school students to examine their smoking prevalence, attitudes, knowledge and behaviors/beliefs. They found that the prevalence of current smoking was $38.2 \%$. Around $94 \%$ of the current smokers believed that health professionals should receive specific training on smoking cessation, and only $21.3 \%$ of the sample received it during their study.

One of the main aims of nursing profession is assisting people in achieving their full health potentials. ${ }^{[29]}$ Nurses, who often interact with patients more frequently than other healthcare professionals do, are in an ideal position to advise and educate their patients about negative consequences of smoking behaviors. ${ }^{[9]}$

Nurses have the best opportunity to deliver smoking cessation interventions during clinical interactions in health- 
care settings. ${ }^{[30,31]}$ Receiving training on smoking cessation increases the likelihood of performing smoking cessation counseling by nurses. ${ }^{[32]}$ In Saudi Arabia, there is no separate educational module on tobacco control in the content of undergraduate nursing curricula. Further, no published literature determined which options for intervention within smoking cessation programs might work better. This may affect the readiness of nursing students to provide adequate and targeted advice to patients concerning their smoking habits.

Most of published tobacco smoking studies on nursing students in the Middle East recruited more male subjects than females. Thus, previously published prevalence of smoking, knowledge, beliefs, and attitudes findings should be viewed with a particular caution due to the limited representation of females.

\section{MethodS}

\subsection{Design}

Using convenience sampling, a descriptive correlational design was used. A cross-sectional, self-reported survey was utilized to collect data during the period from March to May 2016.

\subsection{Setting}

Subjects were recruited from a nursing program that is offered by a governmental university located in Alriyadh, the capital of Saudi Arabia.

\subsection{Sample and recruitment process}

The study subjects were female nursing students, who were within the 3rd and 4th years of their undergraduate study. At the time of data collection, the total population of enrolled students was 134 students. They all were invited and agreed to take part of the study (The response rate reached 100\%). They were all females as no male students were enrolled into the undergraduate nursing program when the data collection was commenced. While assuring them of the anonymity and confidentiality of their responses, nursing students were invited to participate directly by research members. The purpose of the study was explained and students were given time to ask questions. Written informed consent to participate in the study was collected.

\subsection{Measurements}

The study questionnaire consisted of several sections to elicit data about sociodemographic, history and pattern of smoking, knowledge questions concerning smoking, attitudes and beliefs toward smoking. A standardized self-administered questionnaire, the Global Health Professional Student Sur- vey (known as GHPSS), was used. The Centers for Disease Control and Prevention (CDC), World Health Organization (WHO), and Canadian Public Health Association (CPHA) developed the GHPSS in 2005. ${ }^{[33]}$ The GHPSS had been used among students who were attending healthcare schools in other countries. ${ }^{[10,34]}$ It includes questions on demographic characteristics, tobacco use, knowledge and attitudes about tobacco use, exposure to second-hand tobacco smoke, and training received regarding cessation counseling among health professional students. ${ }^{[33]}$ In this study, several questions were added to elicit additional knowledge, beliefs and religious views toward tobacco products use.

\subsection{Ethical considerations}

The study protocol was reviewed and necessary approval was collected from the research ethics committee at the participating university before commencing the data collection.

\subsection{Data management and analysis}

The statistical analyses were performed using the IBM SPSS program. The data were systematically examined for missing data, any inconsistencies and out of range values. Appropriate descriptive statistics (means and standard deviations for continuous variables and frequencies and percents for categorical variables) were calculated for all of the study variables. Spearman rho correlation coefficient statistics were used to assess the relationships between the study variable. Comparisons between the groups of the smokers were carried out using $t$ test for continuous variables or $\chi^{2}$ test for categorical variables. Considering tobacco smoking status as an outcome variable, a logistic regression modeling was invested to identify independent predictors associated with the tobacco smoking status among nursing students. All the statistical analyses were conducted using two-tailed tests and $\alpha=0.05$.

\section{RESULTS}

\subsection{Sociodemographic data and tobacco smoking his- tory and pattern}

Due to the small number of subjects who currently smoke cigarettes only $(n=3)$, and who currently smoke waterpipes only $(n=2)$, and who currently smokes both cigarettes and waterpipes (commonly called 'dual user') $(n=1)$, these subjects were excluded from the current analyses so as not to distort the study results. Thus, the results in this paper represent data from 128 subjects. The average age of our subjects was $21.5( \pm 1.2)$, ranging from 19 to 25 years. They were all Muslims, and most of them $82.8 \%(n=106)$ were singles. Half of the subjects were in the third year of the undergraduate nursing program offered at the study site. 
Almost eighty four percent of the subjects (108 out of 128) reported not smoking tobacco products (not even a single puff or two) throughout their lifetime (i.e., never smokers), while the remaining were former smokers (i.e., ex-smokers who quitted smoking tobacco products). Among former smokers $(n=20), 16$ subjects vs. 7 subjects reported quitting cigarette and waterpipe smoking, respectively. The average age at which first puff of cigarette smoking started was 16.4 $( \pm 4.5)$, and first whole cigarette smoking started was 16.4 ( \pm 4.7 ), ranging from 8 to 23 . Among waterpipe smokers, the average age was a little higher $18( \pm 4.6)$ for both taking first puff and a whole session of waterpipe, ranging from 8 to 22 years. Married former smokers represented $25 \%$ of former smokers and $12 \%$ of never smokers. No statistically significant difference was noted between never smokers and former smokers regarding their marital status. Compared to never smokers, statistically significantly more former smokers were enrolled in the fourth year of the undergraduate nursing program $\left(70 \%\right.$ vs. $\left.46 \%, \chi^{2}=3.80, \mathrm{df}=1, p=.05\right)$.

\subsection{Knowledge about tobacco smoking and environmen- tal exposure to tobacco smoke}

When the subjects were asked, "Do you think that tobacco smoking is harmful to health?", all of them reported 'yes'. Table 1 shows that most of our study subjects had correct answers to the knowledge questions about tobacco smoking. Almost seventy-four percent of them believed that smoking causes nicotine addiction. A statistically significant difference was noted between never smokers and former smokers. More never smokers than former smokers $(94.4 \%$ vs. $75.0 \%$, $\chi^{2}=8.12, \mathrm{df}=1, p<.01$ ) reported that it is 'very likely' or 'likely' that a smoker will avoid or decrease health problems after quitting smoking.

As depicted in Table 1, there were statistically significant differences between the responses of never smokers and former smokers in levels of exposure to environmental tobacco smoke. A smaller percentage of never smokers reported that smoking is allowed inside their own homes, when compared to former smokers $\left(2.8 \%\right.$ vs. $20 \%, \chi^{2}=14.12, \mathrm{df}=3, p$ $<.01)$. Former smokers reported more often $(40.0 \%)$ allowance of smoking inside home in the presence of children compared with never smokers $(15.7 \%)\left(\chi^{2}=6.32, \mathrm{df}=1, p\right.$ $=.01)$. Spearman's rho correlation coefficients showed that being former smoker had two statistically significant weak correlations with allowing smoking inside their homes ( $\rho$ $=0.26, p<.01)$ and allowing smoking inside their homes while children were present $(\rho=0.22, p=.01)$. Thinking that a smoker will likely avoid serious health problems if quit smoking was weakly positively correlated with being never smoker $(\rho=0.25, p<.01)$.

Published by Sciedu Press

\subsection{Attitudes and beliefs toward tobacco smoking}

The vast majority of the subjects expressed positive attitudes towards banning of: tobacco selling to children, advertising of tobacco products, and smoking in restaurants, cafes and all enclosed public places. Former smokers were less positive in regards to banning smoking in restaurants (90\%) when compared to never smokers $(100 \%)\left(\chi^{2}=10.97, \mathrm{df}=1, p<\right.$ $.01)$. Our study subjects believed that health professionals who themselves smoke cigarettes or waterpipe will be less likely to advise their patients to quit smoking $(73.4 \%$ for cigarettes smokers vs. $66.4 \%$ for waterpipe smokers). When compared to former smokers, never smokers were more significantly positive in regards to have a role in giving advice or information about smoking cessation to patients (100\% vs. $\left.90 \%, \chi^{2}=10.97, \mathrm{df}=1, p<.01\right)$. However, about $70 \%$ of the subjects stated that the patient's chances of quitting smoking increases if a health professional advises the smoker to quit tobacco smoking (see Table 2).

The ranked order (most to least) for our study subjects beliefs toward tobacco smoking cessation methods showed 'Gradually decreasing number of tobacco product smoked' (56.3\%) and 'Quit on own (without any help)' (51.6\%) as the first and second most positive beliefs toward possible tobacco smoking cessation methods, while using 'Pamphlets' ranked lowest (12.5\%) (see Figure 1). Former smokers were significantly less positive in regards to using 'formal stop-smoking program' as a helpful method of smoking cessation (20\% vs. $\left.49.1 \%, \chi^{2}=5.78, \mathrm{df}=1, p=.02\right)$ when compared to never smokers.

\subsection{Curriculum/training on tobacco smoking}

In any of their classes in the undergraduate program, around sixty-three percent of our study subjects reported they were taught about the dangers of smoking and 50\% reported discussing reasons why people smoke. Furthermore, 53.9\% stated that they learned that it important to record tobaccouse history as part of a patient's general medical history (see Table 3). Although 11.7\% indicated that they had received formal training concerning tobacco-smoking cessation, significantly more former smokers reported receiving such formal training than never smokers $\left(25 \%\right.$ vs. $9.3 \%, \chi^{2}=4.04$, $\mathrm{df}=1, p=.04)$.

When asked, "Did you learn that it is important to provide educational materials to support smoking cessation to patients who want to quit smoking?", $74.2 \%$ responded 'yes'. In response to the question about the use of nicotine-replacement therapies in tobacco smoking cessation programs, just above the half of our study subjects (54.7\%) stated that they ever heard about the use of nicotine-replacement therapies. Fur- 
ther, a quarter (25\%) of the subjects reported hearing about or Zyban) to help with quitting smoking.

the sometime prescribed antidepressants (such as bupropion

Table 1. Description of responses to knowledge about tobacco smoking and environmental exposure to tobacco smoke questions

\begin{tabular}{|c|c|c|c|c|}
\hline \multirow[t]{2}{*}{ Questions } & $\begin{array}{l}\text { All Subjects } \\
(\mathrm{N}=128)\end{array}$ & $\begin{array}{l}\text { Never Smokers } \\
(\mathrm{N}=108)\end{array}$ & $\begin{array}{l}\text { Former Smokers } \\
(\mathbf{N}=\mathbf{2 0})\end{array}$ & \multirow[t]{2}{*}{$p$} \\
\hline & $\%(n)$ & $\%(n)$ & $\%(n)$ & \\
\hline \multicolumn{5}{|l|}{ Knowledge about Tobacco Smoking } \\
\hline \multicolumn{5}{|c|}{ Do you think that tobacco smoking is harmful to health? } \\
\hline No & $0.00(0)$ & $0.00(0)$ & $0.00(0)$ & \multirow[t]{2}{*}{1.00} \\
\hline Yes & $100.0(128)$ & $100.0(108)$ & $100.0(20)$ & \\
\hline \multicolumn{5}{|c|}{ Do you believe smoking causes nicotine addiction? } \\
\hline No, or Don’t know & $25.8(33)$ & $25.9(28)$ & $25.0(5)$ & \multirow[t]{2}{*}{.93} \\
\hline Yes & $74.2(95)$ & $74.1(80)$ & $75.0(15)$ & \\
\hline \multicolumn{5}{|c|}{ Do you think that shisha smoking is less harmful to a smoker than cigarette smoking? } \\
\hline No, or Unsure & $88.3(113)$ & $88.9(96)$ & $85.0(17)$ & \multirow[t]{2}{*}{.62} \\
\hline Yes & $11.7(15)$ & $11.1(12)$ & $15.0(3)$ & \\
\hline \multicolumn{5}{|c|}{ To what extent do you think the number of cigarettes a person smokes affects his/her future health? } \\
\hline Not very much, or I don’t know & $7.8(10)$ & $6.5(7)$ & $15.0(3)$ & \multirow[t]{2}{*}{.19} \\
\hline Very much, or Much & $92.2(118)$ & $93.5(101)$ & $85.0(17)$ & \\
\hline \multicolumn{5}{|c|}{$\begin{array}{l}\text { To what extent do you think the number of cigarettes a person smokes influences his/her risk of having a heart attack (myocardial infarction) } \\
\text { or a chest pain (angina)? }\end{array}$} \\
\hline Not very much, or I don't know & $7.8(10)$ & $6.5(7)$ & $15.0(3)$ & \multirow[t]{2}{*}{.19} \\
\hline Very much, or Much & $92.2(118)$ & $93.5(101)$ & $85.0(17)$ & \\
\hline \multicolumn{5}{|c|}{ How likely do you think that the heart disease will worsen in a smoker who does not quit smoking? } \\
\hline Very unlikely, Unlikely, or Uncertain & $1.6(2)$ & $1.9(2)$ & $0.0(0)$ & \multirow[t]{2}{*}{0.54} \\
\hline Very likely, or Likely & $98.4(126)$ & $98.1(106)$ & $100.0(20)$ & \\
\hline \multicolumn{5}{|c|}{ How likely do you think it is that you will avoid or decrease serious health problems if you quit smoking? } \\
\hline Very unlikely, Unlikely, or Uncertain & $8.6(11)$ & $5.6(6)$ & $25.0(5)$ & \multirow[t]{2}{*}{$<0.01^{*}$} \\
\hline Very likely, or Likely & $91.4(117)$ & $94.4(102)$ & $75.0(15)$ & \\
\hline \multicolumn{5}{|l|}{ Environmental Exposure to Tobacco Smoke } \\
\hline \multicolumn{5}{|c|}{ Which of the following best describes the rules about smoking inside of your home? } \\
\hline No rules & $14.8(19)$ & $13.9(15)$ & $20.0(4)$ & \multirow{4}{*}{$<.01^{*}$} \\
\hline Never allowed & $59.4(76)$ & $64.8(70)$ & $30.0(6)$ & \\
\hline Not allowed, but there are some exceptions & $20.3(26)$ & $18.5(20)$ & $30.0(6)$ & \\
\hline Allowed & $5.5(7)$ & $2.8(3)$ & $20.0(4)$ & \\
\hline \multicolumn{5}{|c|}{ Inside your home, is smoking allowed in the presence of children? } \\
\hline No & $19.5(25)$ & $84.3(91)$ & $60.0(12)$ & \multirow[t]{2}{*}{$.01^{*}$} \\
\hline Yes & 80.5 (103) & $15.7(17)$ & $40.0(8)$ & \\
\hline \multicolumn{5}{|c|}{ During the past 7 days, on how many days have people smoked where you live, in your presence? } \\
\hline 0 days & $50.8(65)$ & $52.8(57)$ & $40.0(8)$ & \multirow{5}{*}{62} \\
\hline 1 to 2 days & $9.4(12)$ & $9.3(10)$ & $10.0(2)$ & \\
\hline 3 to 4 days & $8.6(11)$ & $9.3(10)$ & $5.0(1)$ & \\
\hline 5 to 6 days & $2.3(3)$ & $1.9(2)$ & $5.0(1)$ & \\
\hline All 7 days & $28.9(37)$ & $26.9(29)$ & $40.0(8)$ & \\
\hline During the past 7 days, on how many days ha & our presence, i & laces other than wh & e you live? & \\
\hline 0 days & $46.9(60)$ & $48.1(52)$ & $40.0(8)$ & \\
\hline 1 to 2 days & $23.4(30)$ & $25.0(27)$ & $15.0(3)$ & 25 \\
\hline 3 to 4 days & $13.3(17)$ & $12.0(13)$ & $20.0(4)$ & .25 \\
\hline 5 to 6 days & $3.1(4)$ & $1.9(2)$ & $10.0(2)$ & \\
\hline All 7 days & $13.3(17)$ & $13.0(14)$ & $15.0(3)$ & \\
\hline
\end{tabular}


Table 2. Description of responses to attitudes toward tobacco smoking questions

\begin{tabular}{|c|c|c|c|c|}
\hline \multirow{2}{*}{$\begin{array}{l}\text { Responding } \\
\text { "Yes" to the question ... }\end{array}$} & $\begin{array}{l}\text { All Subjects } \\
(\mathrm{N}=128)\end{array}$ & $\begin{array}{l}\text { Never Smokers } \\
(\mathrm{N}=108)\end{array}$ & $\begin{array}{l}\text { Former Smokers } \\
(\mathrm{N}=20)\end{array}$ & \multirow[t]{2}{*}{$p$} \\
\hline & $\%$ (n) & $\%(n)$ & $\%(n)$ & \\
\hline Should tobacco sales to children be banned? & $98.4(126)$ & $98.1(106)$ & $100.0(20)$ & .54 \\
\hline Should there be a complete ban of the advertising of tobacco products? & $96.9(124)$ & $98.1(106)$ & $90.0(18)$ & .054 \\
\hline Should smoking be banned in restaurants? & $98.4(126)$ & $100.0(108)$ & $90.0(18)$ & $<.01^{*}$ \\
\hline Should smoking be banned in cafes? & $89.8(115)$ & $91.7(99)$ & $80.0(16)$ & .11 \\
\hline Should smoking in all enclosed public places be banned? & $98.4(126)$ & $99.1(107)$ & $95.0(19)$ & .18 \\
\hline Would you favor increasing taxes on tobacco products? & 85.2 (109) & $87.0(94)$ & $75.0(15)$ & .16 \\
\hline Should health professionals get specific training on cessation techniques? & $92.2(118)$ & $90.7(98)$ & $100.0(20)$ & .16 \\
\hline $\begin{array}{l}\text { Do health professionals serve as "role models" for their patients and the } \\
\text { public? }\end{array}$ & $88.3(113)$ & $88.0(95)$ & $90.0(18)$ & .79 \\
\hline $\begin{array}{l}\text { Should health professionals routinely advise their patients who smoke } \\
\text { cigarettes to quit smoking? }\end{array}$ & $92.2(118)$ & $92.6(100)$ & $90.0(18)$ & .69 \\
\hline $\begin{array}{l}\text { Should health professionals routinely advise their patients who use other } \\
\text { tobacco products (e.g., shisha and cigar) to quit using these products? }\end{array}$ & $92.2(118)$ & $92.6(100)$ & $90.0(18)$ & .69 \\
\hline $\begin{array}{l}\text { Do health professionals have a role in giving advice or information about } \\
\text { smoking cessation to patients? }\end{array}$ & $98.4(126)$ & $100.0(108)$ & $90.0(18)$ & $<.01^{*}$ \\
\hline $\begin{array}{l}\text { Are a patient's chances of quitting smoking increased if a health professional } \\
\text { advises him or her to quit? }\end{array}$ & $71.1(91)$ & $72.2(78)$ & $65.0(13)$ & .51 \\
\hline
\end{tabular}
$* p<.05$.

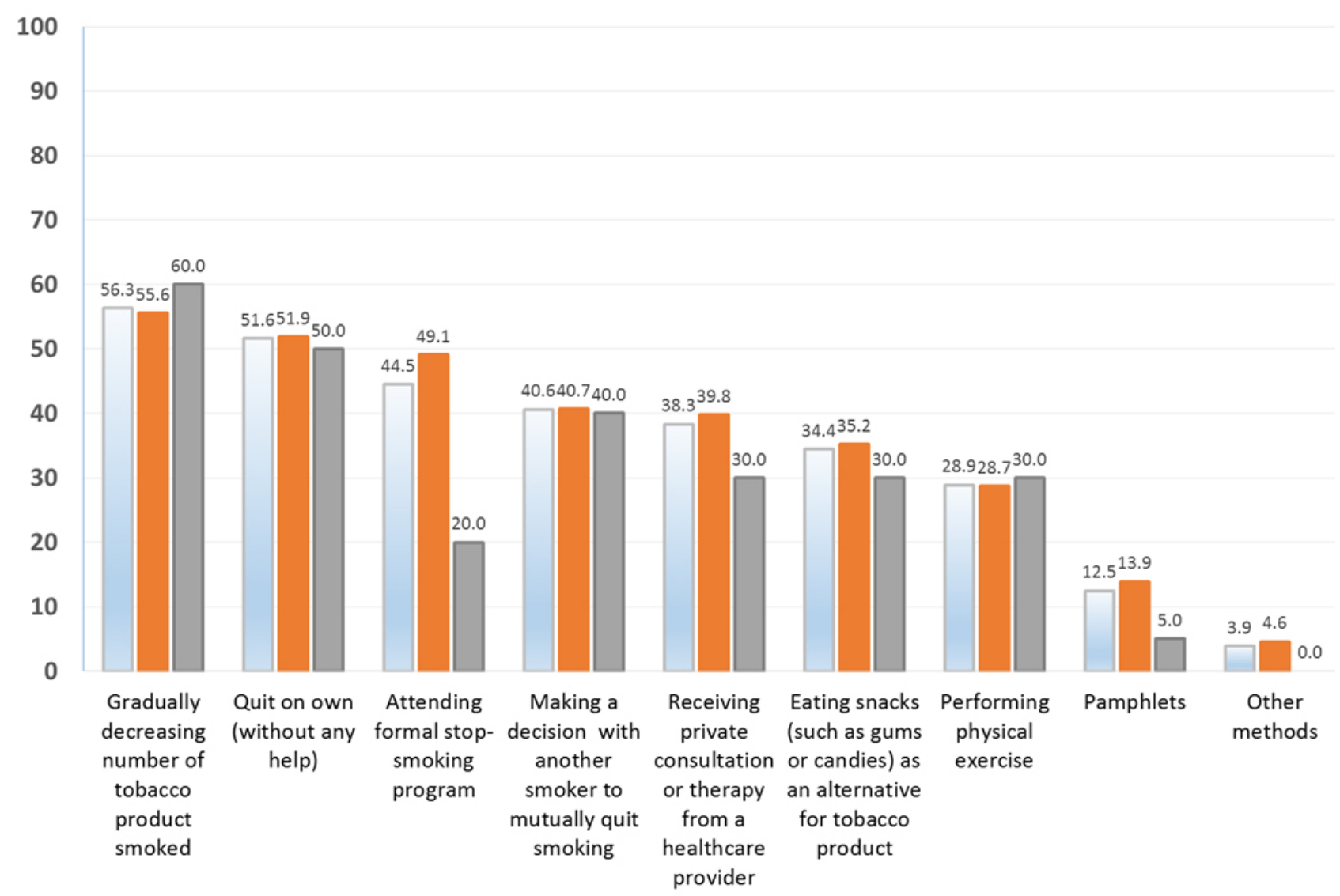

\section{All Subjects $\square$ Never Smokers $\square$ Former Smokers}

Figure 1. Percentage reporting positive beliefs toward tobacco smoking cessation methods 
Table 3. Description of responses to curriculum/training on smoking questions

\begin{tabular}{|c|c|c|c|c|}
\hline \multirow{2}{*}{$\begin{array}{l}\text { Responding } \\
\text { "Yes" to the question ... }\end{array}$} & $\begin{array}{l}\text { All Subjects } \\
(\mathrm{N}=128)\end{array}$ & $\begin{array}{l}\text { Never Smokers } \\
(\mathrm{N}=108)\end{array}$ & $\begin{array}{l}\text { Former Smokers } \\
(\mathrm{N}=20)\end{array}$ & \multirow[t]{2}{*}{$p$} \\
\hline & $\%(n)$ & $\%(n)$ & $\%(n)$ & \\
\hline Were you taught in any of your classes about the dangers of smoking? & $63.3(81)$ & $60.2(65)$ & $80.0(16)$ & .09 \\
\hline Did you discuss in any of your classes the reasons why people smoke? & $50.0(64)$ & $50.0(54)$ & $50.0(10)$ & 1.00 \\
\hline $\begin{array}{l}\text { Did you learn that it is important to record tobacco use history as part of a } \\
\text { patient's general medical history? }\end{array}$ & $53.9(69)$ & $51.9(56)$ & $65.0(13)$ & .28 \\
\hline $\begin{array}{l}\text { Have you ever received any formal training in smoking cessation approaches to } \\
\text { use with patients? }\end{array}$ & $11.7(15)$ & $9.3(10)$ & $25.0(5)$ & $.04 *$ \\
\hline $\begin{array}{l}\text { Did you learn that it is important to provide educational materials to support } \\
\text { smoking cessation to patients who want to quit smoking? }\end{array}$ & $74.2(95)$ & $75.0(81)$ & $70.0(14)$ & .64 \\
\hline $\begin{array}{l}\text { Have you ever heard of using nicotine replacement therapies in tobacco } \\
\text { cessation programs (such as nicotine patch or gum)? }\end{array}$ & $54.7(70)$ & $52.8(57)$ & $65.0(13)$ & .31 \\
\hline $\begin{array}{l}\text { Have you ever heard of using antidepressants in tobacco cessation programs } \\
\text { (such as bupropion or Zyban)? }\end{array}$ & $25.0(32)$ & $24.1(26)$ & $30.0(6)$ & .57 \\
\hline
\end{tabular}
$* p<.05$.

\subsection{Predictors of students' smoking status}

The logistic regression model (see Table 4) was statistically significantly able to estimate smoking status of our study subjects with high sensitivity $(84.4 \%, p<.001)$. Students who were in third year of program, who thought that a smoker who quits smoking tobacco-products would avoid/decrease serious health problems, and who stated that tobacco smoking never been allowed inside their living homes while children were present were more likely be never smokers, while controlling for other independent variables in the regression model.

\subsection{Unique findings about current smokers}

Some findings from the data collected from our study's current smokers, whom data excluded from analyses so as not to skew the data, could be of interest. Almost eighty-three (5 out 6) were single and were enrolled in the third year of the undergraduate nursing program, and $66.7 \%(n=4)$ reported that they had people smoked everyday where they lived during their presence, and half of them agreed to ban smoking in cafes. Regarding their beliefs about the methods of quitting smoking, the highly ranked method they believed in was quitting smoking on their own without any help (66.7\%), while no one believed that private consultation or therapy from a healthcare provider (e.g., a doctor) can be beneficial. Interestingly, one current smoker suggested two unique methods she believed might help to quit smoking, specifically: eating pomegranate and burning incense (aromatic plant and biotic material usually combined with essential oils; called Bukhoor in Arabic) inside the smoking-allowed areas.

Table 4. Logistic regression model of predictor variables and smoking status as a dependent variable

\begin{tabular}{|c|c|c|c|c|c|c|}
\hline \multirow[t]{2}{*}{ Predictor } & \multirow{2}{*}{$\begin{array}{l}\text { Logistic } \\
\text { Coefficient } \\
\text { [B] }\end{array}$} & \multirow{2}{*}{$\begin{array}{l}\text { Standard } \\
\text { Error } \\
\text { [E.R.] }\end{array}$} & \multirow[t]{2}{*}{ Sig. } & \multirow{2}{*}{$\begin{array}{l}\text { Odds } \\
\text { Ratio }\end{array}$} & \multicolumn{2}{|c|}{$\begin{array}{l}\text { 95\% Confidence Interval } \\
\text { [C.I.] for Odds Ratio }\end{array}$} \\
\hline & & & & & Lower & Upper \\
\hline $\begin{array}{l}\text { Marital Status } \\
\text { [the reference: Married] }\end{array}$ & -1.018 & .704 & .148 & 0.36 & 0.09 & 1.44 \\
\hline $\begin{array}{l}\text { Year of Nursing Program Study } \\
\text { [the reference: Fourth] }\end{array}$ & -1.526 & .651 & $.019 *$ & 0.22 & 0.06 & 0.78 \\
\hline $\begin{array}{l}\text { Thinks that a Smoker would Avoid/Decrease Serious } \\
\text { Health Problems when Quitting Tobacco Smoking } \\
\text { [the reference: Very Likely or Likely] }\end{array}$ & 2.274 & .809 & $.005 *$ & 9.72 & 1.99 & 47.47 \\
\hline $\begin{array}{l}\text { Smoking Allowance inside Home } \\
\text { [the reference: Never Allowed] }\end{array}$ & 1.141 & .589 & .053 & 3.13 & 0.99 & 9.93 \\
\hline $\begin{array}{l}\text { Allowing Tobacco Smoking inside Home while } \\
\text { Children are Present } \\
\text { [the reference: } N o \text { ] }\end{array}$ & 1.499 & .639 & $.019 *$ & 4.48 & 1.28 & 15.67 \\
\hline Constant & -0.773 & .868 & .373 & 0.46 & & \\
\hline
\end{tabular}

$* \chi^{2}=25.436, d f=5 .{ }^{*} p<.05$. Never Smoker status was given a value of ' 1 '. 


\section{Discussion}

Our study on female nursing students showed unique and interesting findings that are worth to discuss. Some subjects started smoking early in life ( 8 years old) and it appears that their experimentation of "taking their first puff" of tobacco products had turned them to regular smokers. The early use of tobacco products may result in a development of a severe dependence on nicotine. ${ }^{[35]}$ Similarly, this study found that more former smokers were in their fourth year of the program compared to third year students, similar to Haddad and Malak ${ }^{[15]}$ study findings. Further research work in this area is warranted to explore the likelihood that some consequences of smoking (such as stimulation/state enhancement, social facilitation, weight control, craving/addiction, negative physical feelings, etc.) had ensued among them or not.

Contrary to the findings of Cui et al.'s ${ }^{[14]}$ study that revealed that about 11 and 55 percent of the smoking students thought smoking "not harmful" and "somewhat harmful" respectively, all our study subjects thought that tobacco smoking is harmful to health, and more than $90 \%$ correctly answered the knowledge questions about harmful effects of tobacco smoking on health. Interestingly, all the subjects reported that smoking negatively affect the health, yet more never smokers than former smokers that it is 'likely' or 'very likely' to avoid or decrease serious health problems if a smoker quit smoking. Future studies should be established to explore the lived experiences of formers smokers who developed such understanding.

Even though all our study subjects were Muslims, some expressed that they were not aware about the Islamic legislations regarding neither smoking products nor selling those products. These findings indicate that it is necessary for the nursing curricula to emphasize cultural and religious differences when training on smoking cessation. For instance, tobacco smoking and selling of tobacco products are forbidden behaviors in Islam, and such knowledge may aid some Muslim smokers in quitting their tobacco smoking.

Some subjects reported allowing smoking tobacco products inside their own homes, as well as while children are present. These practices expose all household members to tobacco smoke, increasing the proneness to developing diseases caused by or associated with tobacco smoking. Smoking cessation programs and anti-smoking campaigns should emphasize that recent evidence on the health hazards of first-, second- and third-hand tobacco smoking. ${ }^{[36-41]}$

The findings showed that former smokers less agreed than never smokers to ban smoking in restaurants. The dependency on nicotine that was experienced by former smokers

Published by Sciedu Press may have contributed to that lenient attitude toward enforcing smoking banning. In Saudi Arabia, although several regulations have been instituted to protect the public from tobacco products smoking in public areas, including restaurants, restrictions on tobacco use in public places has not been well enforced. Importance of banning of smoking has been emphasized in the American Heart Association /American College of Cardiology Guideline on Lifestyle Management to Reduce Cardiovascular Risk ${ }^{[42]}$ as well as the European Guidelines on Cardiovascular Disease Prevention. ${ }^{[8]}$ Active monitoring and implementation of these regulations in public places would benefit active smokers along with others in the community.

Less former smokers than never smokers showed positive attitudes that health professionals should have a role in giving advice or information about smoking cessation to patients. This difference could be attributable to their tobacco smoking history. Some nurses who are smokers may fail to give advice to their patients on quitting smoking. ${ }^{[43]}$ Nursing schools should acknowledge the significant role of nurses in smoking cessation interventions among their patients and in promoting smoke-free healthcare facilities. ${ }^{[44]}$ Further research is suggested to explore justifications for such responses along with the specific experiences of former smokers in order to understand their concerns and views regarding the nature of smoking cessation interventions. Nurses should be encouraged to ask their patients about their tobacco smoking status, and to advise smokers to quit smoking. ${ }^{[45]}$

Similar to the findings of Saade et al.'s ${ }^{[20]}$ and Ferrante et al.'s ${ }^{[9]}$ studies, most of our study subjects believed that healthcare professionals should receive specific training on smoking cessation. However, the majority reported that they had not received such intended training in a formal way. Lack of education regarding tobacco control is a barrier for implementing cessation strategies, ${ }^{[46]}$ and the introduction of smoking cessation training would make a positive impact on the knowledge, attitudes and beliefs about tobacco among students and actively assisting patients in quitting smoking. ${ }^{[47]}$

Indicated by low positive perception toward using several smoking cessation methods, most of our study subjects had little awareness toward such methods. This shows the pressing need of adopting a training module on smoking cessation within the undergraduate nursing program curriculum in order to develop the competency in delivering smoking cessation activities.

Considering the potential differences in knowledge, attitudes, and beliefs toward tobacco smoking between current smokers and never or former smokers, our findings regarding the limited number of current smokers could have some valuable 
insight, and could drive future studies to explore tobacco smoking among them.

\section{Conclusion}

The study investigated the knowledge, attitudes and beliefs of female undergraduate nursing students toward smoking. Although most of the subjects correctly responded to knowledge questions about harmful effects of tobacco smoking on health, some had reported allowing smoking tobacco products inside their homes although children are present. This suggests that such knowledge alone may not be enough in and of itself to let them encourage smokers to avoid exposing all household members to tobacco smoke, increasing the likelihood of developing diseases caused by or associated with tobacco smoking. Similarly, banning of smoking in public places including restaurants should be enforced to benefit active smokers along with others in the community.

Overall, the nursing students showed positive agreement on the importance of their role in helping patients with smoking cessation. Yet, former smokers showed lower positive attitudes toward giving advice or information about smoking cessation to patients. Evidence suggested that nurses who are themselves smokers may fail to give advice to their patients on quitting smoking. Nursing schools should acknowledge the significant role of nurses toward smoking cessation interventions.

The majority of our study subjects expressed that they did not receive training on tobacco control in a formal way, and they showed little awareness toward available smoking cessation methods. These findings indicate a need to improve the undergraduate nursing program curricula by adding smoking cessation-training modules, which would include information regarding the consequences, prevention and treatment of smoking.

\subsection{Limitations and strengths}

It is important to acknowledge that this was a cross-sectional study and, thus, it is not possible to make definitive statements regarding causality. Smoking status of students was assessed by self-report, potentially rendering our results less reliable. However, one can assume that smoking status of students was reported reliably to an adequate level since we used anonymity and voluntary recruitment of our sample. The convenience sample may limit the generalizability of the study findings. Given that tobacco smoking prevalence among Saudi adult population, our sample findings are poten-

\section{REFERENCES}

[1] World Health Organization. Tobacco. 2016. Available from: http: //www. who.int/mediacentre/factsheets/fs339/en/ tially subject to low external validity. Nevertheless, strengths of this study also include that sample size was large size, with enrolled students who are from varied geographic cities across Saudi Arabia. Due to the dearth of findings about smoking among Saudi female nursing students and nature of undergraduate nursing curricula, this study added unique findings toward this research phenomenon.

\subsection{Implications and recommendations}

This study establishes the prevalence of tobacco smoking and emphasizes that undergraduate nursing program should provide more attention on smoking behavior and its cessation interventions during preparing future nurses, who are envisioned to be providing counseling sessions to their patients and have the ability to influence their smoking habits.

Our findings add unique evidence on the effect of smoking status on the attitudes and beliefs toward smoking among female nursing students. Given that most undergraduate nursing programs in Saudi Arabia attended by female students, considering these findings when planning and implementing training modules on smoking cessation may strengthen their efforts in reducing smoking rates among their patients during clinical nursing practice. On the other hand, replication of the study among male nursing students is warranted. This would illustrate potential gender differences in tobacco smoking knowledge, behaviors, attitudes, and beliefs within the same culture and healthcare professional groups.

The university may develop and implement anti-smoking campaigns to reach and inform the public regarding the recognized health risks of tobacco smoking and to provide necessary smoking prevention and cessation interventions to smokers.

Given that former smokers of our study showed unique perceptions toward the benefits of quitting smoking on health and toward their roles in giving advice or information about smoking cessation to patients, future research studies are necessary to explore their lived experiences and the consequences of smoking behaviors among them in order to improve forthcoming trainings on smoking cessation interventions.

\section{Conflicts of Interest Disclosure}

The authors declare that no competing financial, professional, or personal interests have influenced the performance or presentation of the work described in this manuscript.

[2] Centers for Disease Control and Prevention. Current Cigarette Smoking Among U.S. Adults Aged 18 Years and Older. 2016. Available from: http://www.cdc.gov/tobacco/campaign/tips/reso urces/data/cigarette-smoking-in-united-states.html 
[3] World Health Organization. WHO Report on the Global Tobacco Epidemic. Country Profile: Saudi Arabia. 2015. Available from: http://www. who.int/tobacco/surveillance/polic y/country_profile/sau.pdf

[4] Ficarra MG, Gualano MR, Capizzi S, et al. Tobacco use prevalence, knowledge and attitudes among Italian hospital healthcare professionals. Eur J Public Health. 2011; 21(1): 29-34. https: //doi.org/10.1093/eurpub/ckq017

[5] Anthonisen NR, Skeans MA, Wise RA, et al. The effects of a smoking cessation intervention on 14.5-year mortality: a randomized clinical trial. Ann Intern Med. 2005; 142(4): 233-9. PMid:15710956 https : //doi.org/10.7326/0003-4819-142-4-200502150-00005

[6] Peto R, Darby S, Deo H, et al. Smoking, smoking cessation, and lung cancer in the UK since 1950: combination of national statistics with two case-control studies. BMJ. 2000; 321(7257): 323-9. PMid:10926586 https://doi.org/10.1136/bmj .321.7257.3 23

[7] Berndt NC, Bolman C, de Vries H, et al. Smoking cessation treatment practices: recommendations for improved adoption on cardiology wards. J Cardiovasc Nurs. 2013; 28(1): 35-47. https: //doi.org/10.1097/JCN.0b013e318231f424

[8] Piepoli MF, Hoes AW, Agewall S, et al. 2016 European Guidelines on cardiovascular disease prevention in clinical practice. Eur Heart J. 2016; 37(29): 2315-81. https://doi.org/10.1093/eurheart j/ehw106

[9] Ferrante M, Saulle R, Ledda C, et al. Prevalence of smoking habits, attitudes, knowledge and beliefs among Health Professional School students: a cross-sectional study. Ann Ist Super Sanita. 2013; 49(2): 143-9.

[10] Patelarou E, Vardavas CI, Ntzilepi P, et al. Nursing education and beliefs towards tobacco cessation and control: a cross- sectional national survey (GHPSS) among nursing students in Greece. Tob Induc Dis. 2011; 9: 4. https ://doi .org/10.1186/1617-9625-9-4

[11] Sotiropoulos A, Gikas A, Spanou E, et al. Smoking habits and associated factors among Greek physicians. Public Health. 2007; 121(5): 333-40. https://doi.org/10.1016/j.puhe. 2006.10.013

[12] Biraghi E, Tortorano AM. Tobacco smoking habits among nursing students and the influence of family and peer smoking behaviour. J Adv Nurs. 2010; 66(1): 33-9. https://doi.org/10.1111/j.13 65-2648.2009.05135.x

[13] Cauchi D, Mamo J. Smoking health professional student: an attitudinal challenge for health promotion? Int J Environ Res Public Health. 2012; 9(7): 2550-61. https://doi.org/10.3390/ijerph9072 550

[14] Cui Y, Ying M, Fan H. Cigarette smoking practice and attitudes, and proposed effective smoking cessation measures among college student smokers in china. Health Educ. 2012; 112(4): 365-79. https://doi.org/10.1108/09654281211237180

[15] Haddad LG, Malak MZ. Smoking habits and attitudes towards smoking among university students in Jordan. Int J Nurs Stud. 2002; 39(8): 793-802. https://doi.org/10.1016/S0020-7489(02 )00016-0

[16] Hestick H, Perrino SC, Rhodes WA, et al. Trial and lifetime smoking risks among African American college students. J Am Coll Health. 2001; 49(5): 213-9. https://doi.org/10.1080/074484801095 96306

[17] Lenz BK. Beliefs, knowledge, and self-efficacy of nursing students regarding tobacco cessation. Am J Prev Med. 2008; 35(6 Suppl): S494500. https://doi.org/10.1016/j.amepre.2008.09.004

[18] Prokhorov AV, Warneke C, de Moor C, et al. Self-reported health status, health vulnerability, and smoking behavior in college students: implications for intervention. Nicotine Tob Res. 2003; 5(4): 545-52.
PMid:12959792 https://doi.org/10.1080/14622200310001 18649

[19] Rigotti NA, Lee JE, Wechsler H. US college students' use of tobacco products: results of a national survey. J Am Med Assoc. 2000; 284(6): 699-705. https://doi.org/10.1001/jama.284.6.699

[20] Saade G, Warren CW, Jones NR, et al. Tobacco use and cessation counseling among health professional students: Lebanon Global Health Professions Student Survey. Le Journal medical libanais The Lebanese Medical Journal. 2009; 57(4): 243-7.

[21] Sinha DN, Singh G, Gupta PC, et al. Linking India Global Health Professions Student Survey data to the World Health Organization Framework Convention on Tobacco Control. Indian J Cancer. 2010; 47 Suppl 1: 30-4. https://doi.org/10.4103/0019-509X.65177

[22] Sychareun V, Hansana V, Choummanivong M, et al. Cross-sectional survey: smoking among medical, pharmacy, dental and nursing students, University of Health Sciences, Lao PDR. BMJ open. 2013; 3(8): e003042. https://doi.org/10.1136/bmjopen-2013-0 03042

[23] Vitzthum K, Koch F, Groneberg DA, et al. Smoking behaviour and attitudes among German nursing students. Nurs Edu in Pract. 2013; 13(5): 407-12. https ://doi .org/10.1016/j .nepr.2012.12.0 02

[24] Al-Haqwi AI, Tamim H, Asery A. Knowledge, attitude and practice of tobacco smoking by medical students in Riyadh, Saudi Arabia. Ann Thorac Med. 2010; 5(3): 145-8. https://doi.org/10.410 3/1817-1737.65044

[25] Azhar A, Alsayed N. Prevalence of smoking among female medical students in Saudai Arabia. Asian Pac J Cancer Prev. 2012; 13(9): 4245-8. PMid:23167322 https ://doi .org/10.7314/APJCP . 20 12.13 .9 .4245

[26] Awan KH, Hammam MK, Warnakulasuriya S. Knowledge and attitude of tobacco use and cessation among dental professionals. Saudi Dent J. 2015; 27(2): 99-104. https://doi.org/10.1016/j.sd entj.2014.11.004

[27] Mandil AM, Bahnassy AA, Aboul-Azm SM, et al. Knowledge, attitude and smoking patterns among nursing and laboratory technology students, Dammam, Saudi Arabia. J Family Community Med. 1999; 6(2): 51-8. PMid:23008604

[28] Centers for Disease Control and Prevention. Saudi Arabia - Nursing Students 2010 (3rd Year Students Only) Global Health Professions Student Survey (GHPSS). 2012. Available from: https://nccd.cdc.gov/GTSSDataSurveyResources/A ncillary/DownloadAttachment . aspx?ID=1064

[29] de Araujo Sartorio N, Pavone Zoboli EL. Images of a 'good nurse' presented by teaching staff. Nurs Ethics. 2010; 17(6): 687-94. https://doi.org/10.1177/0969733010378930

[30] Duaso M, Duncan D. Health impact of smoking and smoking cessation strategies: current evidence. Br J Community Nurs. 2012; 17(8): 356-63. https://doi.org/10.12968/bjcn.2012.17.8.356

[31] Rice VH, Stead L. Nursing intervention and smoking cessation: meta-analysis update. Heart Lung. 2006; 35(3): 147-63. https : //doi.org/10.1016/j.hrtlng.2006.01.001

[32] Heath J, Crowell NA. Factors influencing intentions to integrate tobacco education among advanced practice nursing faculty. J Prof Nurs. 2007; 23(4): 189-200. https://doi.org/10.1016/j.pr ofnurs.2007.01.016

[33] Centers for Disease Control and Prevention. Global Health Professions Student Survey. 2005. Available from: http://www. cdc.go v/tobacco/global/gtss/tobacco_atlas/pdfs/part5.pdf

[34] Warren CW, Jones NR, Chauvin J, et al. Tobacco use and cessation counselling: cross-country. Data from the Global Health Professions 
Student Survey (GHPSS), 2005-7. Tob Control. 2008; 17(4): 238-47. https://doi.org/10.1136/tc.2007.023895

[35] Benowitz NL. Nicotine addiction. N Engl J Med. 2010; 362(24): 2295-303. https://doi.org/10.1056/NEJMra0809890

[36] Jacob P, Abu Raddaha AH, Dempsey D, et al. Nicotine, carbon monoxide, and carcinogen exposure after a single use of a water pipe. Cancer Epidemiol Biomarkers Prev. 2011; 20(11): 2345-53. https://doi.org/10.1158/1055-9965.EPI-11-0545

[37] Jacob P, Abu Raddaha AH, Dempsey D, et al. Comparison of nicotine and carcinogen exposure with water pipe and cigarette smoking. Cancer Epidemiol Biomarkers Prev. 2013; 22(5): 765-72. https://doi.org/10.1158/1055-9965.EPI-12-1422

[38] Kassem NO, Daffa RM, Liles S, et al. Children's exposure to secondhand and thirdhand smoke carcinogens and toxicants in homes of hookah smokers. Nicotine Tob Res. 2014; 16(7): 961-75. https : //doi.org/10.1093/ntr/ntu016

[39] Northrup TF, Jacob P, Benowitz NL, et al. Thirdhand Smoke: State of the Science and a Call for Policy Expansion. Public Health Rep. 2016; 131(2): 233-8. PMid:26957657 https ://doi .org/10.117 $7 / 003335491613100206$

[40] Ramirez N, Ozel MZ, Lewis AC, et al. Exposure to nitrosamines in thirdhand tobacco smoke increases cancer risk in non-smokers. Environ Int. 2014; 71: 139-47. https ://doi.org/10.1016/j.en vint.2014.06.012

[41] Whitehead TP, Havel C, Metayer C, et al. Tobacco alkaloids and tobacco-specific nitrosamines in dust from homes of smokeless to- bacco users, active smokers, and nontobacco users. Chem Res Toxicol. 2015; 28(5): 1007-14. https ://doi.org/10.1021/acs.ch emrestox. 5 b00040

[42] Eckel RH, Jakicic JM, Ard JD, et al. 2013 AHA/ACC guideline on lifestyle management to reduce cardiovascular risk: a report of the American College of Cardiology/American Heart Association Task Force on Practice Guidelines. J Am Coll Cardiol. 2014; 63(25 Pt B): 2960-84. https://doi.org/10.1016/j.jacc.2013.11.003

[43] Radsma J, Bottorff JL. Counteracting ambivalence: nurses who smoke and their health promotion role with patients who smoke. Res Nurs Health. 2009; 32(4): 443-52. https ://doi .org/10.100 2/nur. 20332

[44] Vardavas CI, Bouloukaki I, Linardakis MK, et al. Smoke-free hospitals in Greece: Personnel perceptions, compliance and smoking habit. Tob Induc Dis. 2009; 5(1): 8. https://doi.org/10.1186/1617 $-9625-5-8$

[45] Fiore MC, Tobacco Use and Dependence Guideline Panel. Treating tobacco use and dependence: 2008 update. 2008 ed. Rockville, Md.: U.S. Dept. of Health and Human Services, Public Health Service.

[46] Sarna L, Danao LL, Chan SS, et al. Tobacco control curricula content in baccalaureate nursing programs in four Asian nations. Nurs Outlook. 2006; 54(6): 334-44. https ://doi.org/10.1016/j.ou tlook. 2006.09.005

[47] Molina AJ, Fernandez T, Fernandez D, et al. Knowledge, attitudes and beliefs about tobacco use after an educative intervention in health sciences' students. Nurse Educ Today. 2012; 32(8): 862-7. https://doi.org/10.1016/j.nedt.2011.11.007 